\title{
A FORMAÇÃO DO LEITOR E O ENSINO DA LITERATURA
}

\author{
Ricardo Magalhães Bulhões
}

Doutorando em Letras - UNESP - Assis-SP; Professor da FAI - Adamantina; UNIP-Assis

\section{RESUMO}

Trata-se de relato e pesquisa em andamento. Teoricamente o seu objetivo básico é sugerir certas conexões entre literatura e ensino, verificando em que medida os meios tradicionais de expressão são afetados pelo poder transformador da linguagem, observando também alternativas metodológicas mecânicas que promovem o desinteresse pela leitura de textos literários.

Palavras-chave: Formação do leitor, ensino de literatura, papel do professor; literatura e ensino, leitura e criatividade.

\section{READER EDUCATION AND TEACHING OF LITERATURE}

\begin{abstract}
This is a report of an ongoing research. Theoretically its basic objective is to suggest certain connections between literature and education, verifying to what extension the traditional ways of expression are affected by the transforming power of language, also observing mechanical methodological alternatives, wick promote the lack of interest for literature texts.
\end{abstract}

Key words: Reader education, teaching of literature, teacher role, literature and teaching, reading and creativity. 


\section{O ENSINO DA LITERATURA E A FORMAÇÃO DO LEITOR}

O ensino da literatura, compreendendo literatura como disciplina escolar dos níveis fundamental e médio, pressupõe antigas e novas inquietações, relacionadas às diversas experiências vivenciadas na prática da sala de aula.

Ligado a múltiplos fatores, sempre emergentes - condições econômicas, culturais, políticas, dentre outros - deve ser analisado como algo a ser continuamente construído, sendo, ele mesmo, um permanente "estado" de tensão.

Estado de tensão na medida que o professor de Língua e Literatura depara-se, freqüentemente, com conflitos e indagações fundamentais, sobretudo quando a tônica principal é o aprofundamento do seu próprio papel.

De um modo geral, no diálogo com seus alunos, surgem questões de diferentes vertentes, lançadas informalmente, como por exemplo: para que serve o ensino da literatura? Ou qual seria a sua finalidade e aplicação prática? E aparecem dúvidas quanto à importância e a utilidade do livro didático na sala de aula, dúvidas quanto à representatividade das velhas antologias escolares, e um sem número de indagações que acabam gerando uma certa sensação de crise.

À medida que nos aproximamos das polêmicas colocadas, fala-se mais e mais de crise. Crise dos valores morais, crise do cinema, crise da literatura. Nada mais natural, portanto, que se fale de uma possível crise do ensino de uma determinada literatura escolar, percalços existenciais em que o professor sofre várias pressões e se vê entre Deus e o Diabo.

Como já salientava Laura Mancinelli (1995), no artigo intitulado Literatura e pessoa histórica, "a literatura, assim como a música e a arte figurativa, é considerada uma produção sem aplicação prática. É contestada com mais intensidade apenas porque é mais amplamente ensinada e muitas vezes imposta". Segundo a autora, "a música e a história da arte também seriam contestadas se fossem ensinadas de maneira maciça nas escolas".

Todas essas inquietações foram devidamente levantadas e discutidas por três pesquisadoras que entrecruzaram diferentes abordagens e apontaram inadequações metodológicas relacionadas a não consideração da esteticidade da Literatura. Falamos dos trabalhos Literatura-Ensino - Uma problemática, de Maria Fraga Rocco; e Literatura: a formação do leitor, das autoras Maria da Glória Bordini e Vera Teixeira de Aguiar.

Nosso texto, aqui constituído, tem em vista a preocupação de sublinhar apenas um determinado assunto, no meio desse território livre e movediço. Optamos por abordar alguns aspectos problemáticos referentes à aplicação de métodos de estudo no ensino de uma literatura escolar, que geralmente segue um modelo preestabelecido pelo livro didático.

Para começar, foi preciso resgatar alguns conceitos básicos sobre o papel e função da literatura, trazendo à superfície o texto do professor Antonio Cândido, A literatura e a 
formação do homem, pertencente à revista "Remate de Males" (1999).

Escrito com docilidade e clareza, sua análise apresentou-se - inicialmente - como uma espécie de instância condutora, que iria respaldar as demais.

Para Antonio Cândido, o ensino da literatura não pode partir de um ponto de vista estritamente pedagógico, seguindo os requisitos das normas vigentes. "A literatura pode formar, mas não segundo a pedagogia oficial, que costuma vê-la ideologicamente como um veículo da tríade: o verdadeiro, o bom, o belo, definidos conforme os interesses dos grupos dominantes". $\mathrm{Na}$ verdade, "longe de ser um apêndice da instrução moral e cívica, ela age com o impacto indiscriminado da própria vida e educa como ela, com altos e baixos, luzes e sombras".

Não sendo, muitas vezes, apresentada como obra de arte, possuidora de valor estético, a literatura acaba se prestando a exprimir valores ideológicos ou moralizantes, tornando-se o que Antonio Cândido chamou de "apêndice".

Vários autores literários consagrados são abordados nos livros didáticos como vultos nacionais. Personalidades importantes em momentos de afirmação dos chamados "valores nacionais"; exaltação da personalidade do escritor e a preocupação em fixar para a posteridade a sua imagem como patrimônio, consagrando como oficial o saber das classes dominantes.

Cumpre-nos destacar, novamente, Laura Mancinelli, no trabalho já aludido, segundo a qual o ensino da literatura só adquire validade na medida que demonstra que tanto a produção literária como as teorias sobre literatura são parte integrante e indissolúvel de um processo histórico que contém em si todas as formas do saber, desde o saber das classes dominantes, consagrado como oficial, até o saber das classes subalternas, em grande parte ignorado e sempre correndo o risco de sucumbir".

Interessa a todos os professores que procedimento se deve adotar para tirar o maior "rendimento" possível de uma leitura. Uma leitura, que além do conhecimento lingüístico propriamente dito, promova um repertório de informações exteriores ao texto.

No terceiro capítulo do livro LiteraturaEnsino: Uma Problemática - Maria Tereza Fraga Rocco (1992) levantou, numa pesquisa piloto realizada com professores em escolas da capital e da grande São Paulo, problemas de várias ordens.

O primeiro problema com o qual se deparou, nas entrevistas realizadas com professores, dizia respeito ao próprio conceito de ensino de literatura e seus objetivos. As afirmações feitas revelavam "ausência de critérios, concepções distorcidas, confusões conceituais" onde prevalecia "a idéia de que literatura é uma coisa e texto outra, onde são privilegiados os aspectos da biografia do autor, aquisição de cultura, um tipo de história..."

Uma outra estratégia apontada pela autora, muito utilizada até hoje, é a de entender o texto seguindo uma orientação histórica, sociológica ou psicológica, não havendo uma preocupação com o objeto estético, no caso a obra literária.

Assim sendo, o livro didático acaba 
adquirindo um caráter aleatório e superficial, distanciando-se dos valores estéticos, deixa de ser um conjunto de métodos de abordagem e produção textual. Podemos dar um bom exemplo desse tipo de leitura promovida pelo livro didático Língua, Literatura e Redação volume 3 , do consagrado José de Nicola.

No capítulo quatro, do referido livro, temos um fragmento de Os Sertões, de Euclides da Cunha. O parágrafo escolhido mostra um Euclides imaginoso, perfeito contador de histórias na caracterização do personagem Antônio Conselheiro. Eis um pequeno trecho:

"E surgia na Bahia o anacoreta sombrio, cabelos crescidos até aos ombros, barba inculta e longa; face escaveirada; olhar fulgurante; monstruoso, dentro de um hábito azul de brim americano; abordoado ao clássico bastão em que se apoia o passo tardo dos peregrinos..."

Depois do fragmento, o autor Nicola chama a atenção para o perfil carismático de Antônio Conselheiro, dizendo que esse seria um representante natural do meio em que nasceu. $\mathrm{Na}$ seqüência, prossegue com perguntas eminentemente ligadas à história $\mathrm{e}$ à sociologia, fazendo perguntas sobre o momento histórico, conceito de positivismo, determinismo etc.

Segundo Maria Glória Bordini e Vera Teixeira de Aguiar (1988), no indispensável texto $A$ formação do leitor - alternativa metodológica - o esvaziamento do ensino da literatura se acentua por diversos motivos. Dentre eles as autoras apontam: a inexistência de uma leitura descompromissada, a falta de estímulo da criatividade e do senso crítico, recorrência de fórmulas prontas e o uso dominante do livro didático com textos fragmentados e com preocupações meramente gramaticais. Ressaltam que o texto literário é pretexto para o estudo da gramática e não é vinculado à experiência de vida do aluno.

Ainda dentro dessa linha de pensamento, Laura Mancinelli demonstra-nos "que muitas vezes os alunos gostam da literatura, ou mantém com ela uma relação de amor e ódio. Instintivamente a amam, mas por uma espécie de lógica pragmática a rejeitam". Em nome de uma prática mais emancipatória, ela assinala com propriedade: "... não acredito que seja suficiente dizer que o estudo crítico da literatura, feito através da aplicação de um método científico, acostuma a mente à análise dos fatos da existência, conferindo-lhe um habitus crítico útil em qualquer circunstância". E acrescenta mais adiante "o nosso papel de professores se frustraria gravemente se não acreditássemos na sua real validade e, portanto, na necessidade existencial de conhecê-la".

Essas considerações só vieram enfatizar mais ainda um aspecto sedutor. Antes de se tornar disciplina escolar a literatura insinua-se, sem as elaborações ou critérios pedagógicos que buscam um determinado fim. Ela substitui a onipotência do saber pragmático pela visão do enigmático, propõe uma transgressão das convenções sociais e dos limites morais.

O professor Alfredo Bosi declara no livro $A$ Formação do Leitor das autoras mencionadas acima: "não sei se é possível constituir uma metodologia muito precisa, como já se fez em matemática ou nas ciências biológicas em que o 
próprio objeto é mais preciso. Aqui, estamos diante de um ponto de convergência de conhecimentos históricos, filológicos, de exigências, de gosto. Enfim, uma didática da literatura teria que lidar com um número muito alto de variáveis".

Assim, como nos apontou Bosi, o gosto pelo texto escapa freqüentemente de um modelo teórico preestabelecido. Geralmente, o gosto pela leitura surge livremente; às vezes em casa, ou folheando revistas numa banca de jornal, num papo informal com amigos etc.

Conforme avaliou Fraga Rocco, entrevistando alunos do ensino médio, grande parte dos estudantes não gosta de ler na escola. Só o fazem quando se trata de exigência, obrigatoriedade da área de Língua Portuguesa. Na verdade, gostam de ler fora do ambiente escolar. Admitem total desinteresse pela leitura promovida na escola. Ainda segundo Fraga Rocco, há uma galeria interminável de obras, por eles citadas, como sendo "horrível", que vem desde de Gil Vicente, passando por Alencar, até chegar a Machado de Assis ou mesmo Graciliano Ramos.

A partir desses resultados insatisfatórios, a autora estabelece um parecer, dizendo: "em termo de ensino para adolescentes e pré-adolescentes, acreditam não ser a obra literária distante no tempo a mais aconselhável". Sugere que o professor deva iniciar seu trabalho por meio de textos contemporâneos, mais próximos da realidade do aluno.

Contrariando o modo estabelecido por Fraga Rocco, achamos que se torna difícil precisar um momento ideal como instrumento de motivação. À primeira vista, acreditamos numa apresentação diversificada das obras, na capacidade de convivências possíveis entre textos distanciados diacronicamente. Não consideramos que esta retomada de obras passadas venha a provocar o desinteresse e o afastamento do aluno.

Mostra disso é o crescente interesse, por parte dos alunos, por poetas de séculos passados, como Gregório de Matos, Álvares de Azevedo e mesmo Jorge Amado. O professor João Alexandre Barbosa (1999) enxerga com muita clareza essa questão: "na verdade, a luta contra métodos tradicionais de ensino da literatura, com resultados positivos inquestionáveis, muitas vezes descamba para a recusa da própria tradição, sem a qual não é possível o estudo, ou mesmo a compreensão, não apenas da literatura, mas das humanidades em geral. Não, é claro, de uma tradição que veja o passado como objeto apenas arqueológico ou arquivístico, mas de uma consciência de que as obras do presente estão sempre informadas pelo conhecimento das tensões que articulam tempos diversos e que, por isso, a rasura do passado significa sempre o empobrecimento do objeto a ser estudado".

Existe, enfim, um esvaziamento do ensino da literatura, o destinatário a quem se dirige este ensino convive permanentemente com fontes diversas de estimulação da fantasia, outros veículos e linguagens, como cinema, televisão e a própria Internet. Maria Glória Bordini e Vera Teixeira de Aguiar enfatizam que o primeiro passo para a formação do leitor se dá através de uma real aproximação desse universo massificado. O livro didático, além da cultura 
oficial, deveria contemplar a junção destas linguagens.

Fraga Rocco observa, como dado preocupante, o fato de que são adotados livros cujos títulos tragam palavras mágicas, do tipo Comunicação \& Expressão. Segundo a autora, isso ocorre tanto em livros didáticos de $1^{\circ}$ quanto de $2^{\circ}$ grau. Outro aspecto negativo sublinhado são os roteiros dados, que já trazem pré-determinados os critérios das análises, inclusive com respostas prontas no tão famoso livro do professor.

Não há menor dúvida de que a difusão do livro e da leitura no Brasil ficou a cargo da escola, principalmente após a revolução de 1.930, a partir da ampliação da rede pública e da organização dos diferentes graus de ensino. Faz-se necessário transcrever aqui uma longa apreciação de Regina Zilberman (1988) que consideramos fundamental:

"Num primeiro momento, confinou leitura à alfabetização, isto é, aprendizagem e emprego do código escrito segundo a norma urbana culta. (...). A seguir, associou leitura com o conhecimento da tradição literária, valorizando o passado da literatura nacional e os escritores que então pontificaram.

Estes, por seu turno, raramente são consumidos por via direta, e sim através da mediação do principal meio de leitura da escola brasileira: o livro didático, descendente das apostilas e seletas de décadas passadas. Porém, o êxito do livro didático, cuja a produção aumenta à medida que cresce a população estudantil, atravessando os graus de ensino e, hoje, confortavelmente instalado, com toda a propriedade, na universidade, só foi possível porque vigora ainda a dificuldade de acesso a outro tipo de livro."

No passado, na primeira metade do século $X X$, o aluno era convidado a se sensibilizar para o mundo das letras, percorrendo a biografia trágica ou heróica dos autores, vista sobre prisma idealista. $\mathrm{O}$ autor dialogava com seus leitores, valendo-se, de julgamentos sábios, transmitidos pelos clássicos numa espécie de celebração litúrgica.

Hoje, um novo tratamento é dado à biografia heróica dos cânones. A didatização desta biografia, heróica- trágica, não condiz com a expectativa dos alunos, não possibilita a intertextualidade anterior, que produzia um efeito de catarse, um dialogismo entre as figuras míticas dos autores.

No presente, o olho de "pirata" de Camões, destacado nos relatos biográficos e gravuras exageradas, vira, facilmente, através da mediação do professor, motivo de "chacota", já que tornou-se anacrônica a perspectiva trágica. No seu lugar, nos deparamos com o efeito cômico, inserido- acidentalmente- a partir de um novo dialogismo. A elevação dos autores, nas antologias e florilégios, mostrava-se associada a um objetivo didático, mesmo que de forma vaga.

$\mathrm{Na}$ verdade, acreditava-se que, lendo ou celebrando cânones, os alunos, assimilariam o domínio de uma escrita exemplar.

$\mathrm{Na}$ avaliação de tal prática, Samir Mesenari (2002) lembra que a literatura estava presente nestas compilações, havia sim um vasto 
programa de literatura, ou melhor, de história da literatura, mas nunca se apurou se essas leituras realmente interferiam nas redações escolares. Por exemplo, "o estudo da escola romântica e a leitura de românticos não garantiam um estilo romântico na redação escolar."

Dentre os organizadores de antologias e florilégios, o professor João Rodrigues da Fonseca Brandão foi um dos pioneiros com a compilação do florilégio brasileiro da infância, obra que reunia sonetos líricos de Gregório de Matos, poemas bucólicos de Tomás Antônio Gonzaga, hinos de Gonçalves de Magalhães, canções de Gonçalves Dias e vários outros autores.

Percorrendo algumas antologias predominantes no início do século $\mathrm{XX}$, nossa questão fundamental era saber qual o critério estabelecido por estes organizadores de antologias. Nossa especulação evidenciou algumas contradições. $O$ valor dos trechos escolhidos dependia inteiramente do julgamento do compilador, no qual reunia num só volume fragmentos considerados representativos sem se quer justificar o critério desta representatividade. Para complicar, estes textos ficavam relegados a prática de exercícios incansáveis, averiguações lingüísticas, etimológicas, semânticas, referências históricas e tantas outras apreciações.

Além de desviarem os leitores da consulta direta dos autores, prevalecia, ainda, o critério da notabilia, a escolha dos textos consagrados, passagens fora de seu contexto original. Encontramo-nos aqui diante de um dos maiores problemas que perduram até hoje nas apostilas dos cursos prévestibulares, de Castro Alves sempre se repete aquele incansável pedaço hiperbólico do Navio Negreiro, existe uma fácil tendência à simplificação das obras.

Vale lembrar que a prática da leitura foi ostensivamente valorizada no século XVIII, objetivando a propagação dos ideais iluministas que a burguesia ascendente pretendia impor à sociedade da época. Nesse sentido, acrescenta Regina Zilberman:

"Valorizando o livro enquanto
instrumento de cultura e usando-o
como arma contra a nobreza feudal
que justificava seus privilégios
evocando a tradição que os
consagrara, os pensadores iluministas
procuraram solapar uma ordem de
conceitos a até então dita como
inquestionável e reivindicaram um
modo de pensar apoiado tão somente
no exercício do raciocínio e na
verificação para assegurar suas
certezas, abolindo o prestígio da magia
e da religião."

Em seguida, constata outro ponto fundamental:

"Os iluministas inauguram, de um lado o racionalismo contemporâneo que confere à ciência uma importância até aí desconhecida por ela, de outro, uma ideologia da leitura, baseada na crença de que a educação, a que se tem acesso pela aquisição do saber acumulado em livros, é a condição primeira de uma bem sucedida escalada social." 
Sob esse ponto de vista, será portanto sensato considerarmos a leitura como uma espécie de propriedade que se manifesta,de forma pragmática e utilitarista.O acesso ao livro era fundamentalmente voltado para a alfabetização,o que promoveria, naturalmente, ascensão social.

O surgimento efetivo de um público leitor, deve ser visto só a partir do final do século XVIII, com o nascimento do mundo burguês, encorajado pelas transformações políticas, econômicas e culturais. Encontramo-nos aqui diante de vários fatores. É necessário reconhecê-los por intermédio de uma colocação de Marisa Lajolo (2001):

"Com a vitória política da burguesia, na França de 1789, começa um ciclo cultural novo. Do outro lado do Canal da Mancha, na Inglaterra, a industrialização criava um modo novo de produção. Desaparecia o artesão e em seu lugar aparecia o operário. Entre o operário e a mercadoria que ele produzia, estavam as máquinas, cada vez mais aperfeiçoadas.

Para fazer a máquina funcionar, o operário precisava saber ler. Abriram-se escolas. A alfabetização espalhou-se, a difusão da leitura ampliou muito o mercado disponível para livros."

Rompido o isolamento, paralelamente, a literatura romântica passa a conquistar de vez, através dos folhetins, uma prática mais democrática de leitura, uma maior liberdade centrada no sentimentalismo e na fantasia.

No Brasil, a história da leitura mergulha no interior de vários territórios. Inicialmente, com o declínio da lavoura, o crescimento gradativo dos centros urbanos, sobretudo com a vida da corte portuguesa em 1.808, tivemos uma compreensível mudança de cenário.

Com a expansão, mesmo que lenta, desse novo mundo, outras convenções adquirem legitimidade. Percebe-se, de forma mais ostensiva, uma preocupação com a formação educacional dos filhos dessa oligarquia agrícola. Alguns livros registram essa preocupação. João Antônio A. Antonil, jesuíta e cronista, faz, em 1.711 uma comparação entre o civilizado e "tabaréu". Tal fragmento, garimpado do indispensável estudo A Leitura Rarefeita, das autoras Regina Zilberman e Marisa Lajolo (1991), vale a pena ser destacado: "Criá-los tabaréus, que nas conversações não saberão falar de outra cousa mais que do cão, do cavalo e do boi."

Sérgio Buarque de Holanda atesta que, no âmbito da vida privada, na primeira metade do século XIX, os lavradores e donos de engenho passam a incentivar seus filhos a terem certas virtudes intelectuais. O historiador salienta a importância dada aos títulos honoríficos como por exemplo anel de grau e a carta de bacharel. Jovens alunos que ocupariam funções citadinas, na política, no judiciário, ou mesmo em algum cargo burocrático no império e posteriormente na república.

Pode-se mesmo dizer que o interesse pelo ensino médio, só ficou mais evidente, sobretudo, a partir de 1.850 quando começa a aumentar o número de cursos superiores no Brasil. Porém, o acesso ao ensino superior não dependia de exames de seleção que exigiriam freqüência no ensino secundário, tornando-o supérfluo e dispensável. 
É interessante notar, que, a motivação pelo saber, acessível a poucos, parece ter-se fundado numa concepção que transcende a racionalidade. A leitura teria um caráter ornamental, uma virtude a ser degustada pouco a pouco por homens nobres e livres.

Com muita precisão, o autor de Raízes do Brasil, revive este momento: "O trabalho mental, que não suja as mãos e não fatiga o corpo, pode constituir, com efeito, ocupação em todos os sentidos digna de antigos senhores de escravos e dos seus herdeiros. Não significa, forçosamente, neste caso, amor ao pensamento especulativo-a verdade é que, embora presumindo o contrário, dedicamos, de modo geral, pouca estima às especulações intelectuais- mas amor à frase sonora, ao verbo espontâneo e abundante, à erudição ostentosa, à expressão rara. É que para bem corresponder ao papel que, mesmo sem o saber, Ihe conferimos, inteligência há de ser ornamento e prenda, não instrumento de conhecimento e de ação."

O apreço exagerado ao livro, visto como artefato luxurioso, livro como página impressa, pode também ser notado a partir da figura notável do nosso imperador Dom Pedro II.

Sendo uma figura representativa dessa tentativa de formação de uma intelectualidade nacional, nosso monarca foi uma espécie de mecenas, freqüentador assíduo de exposições de quadros e um profundo admirador da página impressa. Tempo houve em que o livro, em si, sinalizaria a busca por uma vida mais refinada, civilizada, citadina. $O$ processo de formação de uma intelectualidade nacional, iniciada em câmera-lenta por Dom João VI- com a criação da Biblioteca Nacional e Pública da Corte, organizada precariamente com livros trazidos pelo próprio imperador- ganhava agora um efeito maior.

Assumindo um papel de monarca ilustrado, Dom Pedro apoiou oficialmente a criação do IHGB, que funcionaria no Paço Imperial, órgão responsável por uma escrita sobre a história do Brasil, escrita por seus próprios compatriotas.

Por essa ocasião, tivemos também, no dia oito de Abril de 1.880, a inauguração da Escola Normal da Corte, na augusta presença da sua majestade imperial, sob a presidência do diretor interino Benjamin Constant Botelho de Magalhães, escola responsável pela formação de professores do nível de instrução primária.

Sérgio Buarque de Holanda (1986), localiza a grandeza deste nosso imperador ilustre:

"Dom Pedro, que foi, ao seu tempo, um protótipo da nossa intelectualidade oficial, levou a devoção aos livros a ponto de se dizer dele, com alguma injustiça, que a praticou mais assiduamente do que serviu aos negócios do Estado."

No entanto, posteriormente, mesmo com a pressão de fatores externos, preocupação dos partidários da República com um analfabetismo que atingia mais de $70 \%$ da população, o ensino permaneceu restrito a um pequeno grupo oriundo das oligarquias rurais, que mandava seus filhos para a Europa ou algumas capitais do próprio país.

A leitura regular de obras literárias permanece como "ornamento" de poucos e esbarra na falta de um público leitor expressivo. Outra dificuldade seria a própria escassez de publicações. O público leitor limitava-se a 
anônimos leitores de folhetins, jornalistas, estudantes, algumas moças, e os homens das letras em geral.

Não há menor dúvida de que a difusão do livro e da leitura no Brasil ficou a cargo da escola, principalmente após a revolução de 1.930, a partir da ampliação da rede pública e da organização dos diferentes graus de ensino.

Os manuais ou antologias escolares atuantes nos arredores de 1.930, oferecem alguns protocolos de uma sociedade em constante formação. De modo geral, enxerga-se um certo encantamento pela busca de uma verdade apoiada na cientificidade positivista, na qual defende a especulação do conhecimento por meio das pressuposições teóricas de um especialista.

Cria-se, então, o mito do especialista. Um representante institucionalmente reconhecido e autorizado conforme critérios da classe dominante; uma figura ilustre, diferenciada por saber configurar um modelo cultural, podendo, assim, transmiti-lo para seus concidadãos.

Sabemos que não existe um modelo mágico na prática pedagógica centrada na natureza do literário, o que não significa dizer que não existam caminhos possíveis, mecanismos que possam apresentar resultados satisfatórios e fujam dos moldes automatizados de aplicação.

\section{REFERÊNCIAS BIBLIOGRÁFICAS}

BARBOSA, João Alexandre (1999). Entre livros. SP: Ateliê Editorial. p. 18
BORDINI, Maria da Glória \& AGUIAR, Vera Teixeira de (1988). Literatura: a formação do leitor, alternativas metodológicas. Porto Alegre: Mercado Aberto. p.27

CÂNDIDO, Antonio (1999). Remate de males. Campinas: Unicamp - Revista do Departamento de Teoria Literária. p.05

HOLANDA, Sérgio Buarque (1986). Raízes do Brasil- Campanhia das Letras. p.147

LAJOLO, Marisa (2001). Literatura: Leitores e Leitura. São Paulo- Moderna. p. 31

LAJOLO, Marisa e ZILBERMAN, Regina (1991). A Leitura Rarefeita- Brasiliense p.93

MANCINELLI, Laura (1995). Literatura e "pessoa histórica". in: Papéis Avulsos. Assis: Unesp. p.27

MESERANI, Samir (2002). O Intertexto Escolar. Cortez $4^{\circ}$ Edição.p.35

ROCCO, Maria Thereza Fraga (1992). LiteraturaEnsino: Uma Problemática. Ática. p.109

ZIIBERMAN, Regina (1988). A Leitura e o Ensino da Literatura.- São Paulo- Contexto. p. 48 